\title{
LOURENÇO DE SALZEDO EN ROMA. Influencias del Manierismo romano en la obra del pintor de la reina Catarina de Portugal *
}

\author{
POR \\ VITOR SERRÃO \\ Instituto de Historia del Arte \\ Facultad de Letras de Lisboa
}

\begin{abstract}
Sólo en fecha reciente la Historia del Arte evaluó desde otro punto de vista la obra de Lourenço de Salzedo, un pintor bastante interesante de origen sevillano que pasó a la corte portuguesa, donde, desde 1564, por lo menos, hasta 1577, fecha de su muerte, será pintor de la Reina Catarina de Austria, viuda de D. Joao III. Las recién restauradas tablas que pinta entre 1570-1572 para el retablo mayor del Monasterio de los Jerónimos en Lisboa, después de frustradas diligencias junto a Felipe II para que otros viniesen a pintarlas (Gaspar Becerra, Franz Floris y Francisco de Urbina fueron algunos de los nombres propuestos) muestran una profunda cultura italianizante sólo posible de adquirir con una práctica artística en Roma. Testimoniamos que, de hecho, Salzedo pasó por la ciudad papal en los años centrales del siglo XVI - tal como Gaspar Becerra, Pedro Roviale o el portugués Antonio Campelo-, asimilando ahí los ecos de la Bella Maniera romana junto a las obras miguelangelescas tanto de Girolamo Siciolante da Sermoneta como de Daniele da Volterra, Francesco Salviati y Pellegrino Tibaldi.

Palabras clave: Lourenço de Salzedo, Manierismo, Roma. Lisboa, Monasterio de los Jerónimos, Campelo, Girolamo da Sermoneta, Daniele da Volterra, D. Catarina de Austria.

Only in recent years have the works of Lourenço de Salzedo, a quite interesting painter from Seville who worked at the Portuguese court for queen Catherine of Austria (widow of king Joao III), from approximately 1564 to 1577 (year of his death), begun to be regarded in a new light. The recently restored panels that he painted between 1570 and 1572 for the main altarpiece of the Jeronymite Monastery of Lisbon display a profound knowledge of Italian culture, possible only for one who had studied in Rome. In effect, Salzedo was in the city of the Popes toward the middle of the sixteenth century - as were Gaspar Becerra, Pedro Roviale or the Portuguese artist Antonio Campelo - assimilating echos of Roman Bella Maniera painting in the works of the followers of Michelangelo - Girolamo Siciolante da Sermoneta, Daniele da Volterra, Francesco Salviati and Pellegrino Tibaldi.
\end{abstract}

Key words: Lourenço de Salzedo. Mannerism. Rome. Lisbon, Jeronymite Monastery. Campelo. Girolamo de Sermoneta. Daniele da Volterra. Catarina de Austria.

* El autor agradece el apoyo recibido de la Fundação para a Ciência e a Tecnologia (FCT) que subsidió su investigación en Roma (octubre-noviembre de 2000), así como los enriquecedores intercambios de impresión sobre el Manierismo habidos con Gonzalo Redín Michaus, Antonio Urquizar Herrera, Maria José Redondo Cantera, Isabel Mateo Gómez y Nicole Dacos-Crifó. 
Sólo con el proceso de restauración de las tablas de la capilla mayor del Monasterio de Santa Maria de Belém (o de los Jerónimos) ${ }^{1}$ le fue posible a la Historia del Arte reevaluar la fina personalidad artística del pintor Lourenço de Salzedo. Este artista era, hasta fecha reciente, una mera referencia en las listas de nombres del arte portugués sin obra segura atribuible, a pesar de las referencias elogiosas de algunos autores sobre sus aptitudes, como es el caso del cronista Fray Manuel Baptista de Castro, que le llama «el gran pintor Salzedo» precisamente al respecto de las pinturas del altar de Santa Maria de Belém. Esos cuadros que estaban toscamente repintados y casi no dejaban apreciar sus valores, acabaron por revelar altas cualidades formales e inventivas del pintor y revelar su sólida educación en los circuitos manieristas romanos de circa 1550

Hoy se sabe que Lourenço de Salzedo $(1530 ?-\dagger 1577)$ era de origen español, acaso andaluz (se documentan otros artistas de apellido Salzedo en Sevilla, Córdoba y Granada en el siglo XVI, algunos de ellos posiblemente sus parientes) ${ }^{2}$ y que pasó a la corte portuguesa después de las prácticas en Roma. Fija su residencia en Lisboa, donde a partir de 1564, por lo menos y hasta 1577 , fecha de su muerte, será pintor de la casa de la Reina Dña. Catarina de Austria, viuda de D. Joao III de Portugal, y producirá un conjunto de las obras más relevantes del Manierismo portugués. Se ignora aún la fecha y lugar precisos de su nacimiento, pero recordando la valiosa declaración de Francisco Pacheco en el Libro de descripción de verdaderos retratos de ilustres y memorables varones (Sevilla, 1599) en relación a Francisco Venegas, otro pintor andaluz que se asienta en la corte de Lisboa, después de aprender en Sevilla en el taller de Luís de Vargas (1506-1567), puede sugerirse que Salzedo fuese sevillano y hubiese seguido el mismo camino de Venegas. Si fuese así, fue en el ambiente esplendoroso del taller de Vargas ${ }^{3}$, el mejor maestro sevillano de esta generación, educado en Roma en la esfera de Pierino del Vaga (de quien fue discípulo) y de Francesco Salviati (por quien fue manifiestamente influenciado) donde Salzedo podría haber tomado el primer contacto con la novedad de la Bella Maniera romana. Pero no dejaría de seguir a esa experiencia el contacto directo con las vanguardias artísticas de Roma, que seguramente conoció antes de instalarse en la corte portuguesa, como su obra demuestra, pues además de estudiar dibujos y grabados de antigüedades Salzedo contactó de visu con las obras de los maestros más considerados (Pierino del Vaga, Daniele de la Volterra, Girolamo Siciolante de la Sermoneta, Francesco Salviati, Pellegrino Tibaldi y, bien entendido, Miguel Ángel Buonarroti), y consigue asumir una maniera personal, actualizada, moderna y fácilmente reconocible.

Después de 1564, Lourenço de Salzedo (Salcedo, o Sauzedo, como aparece referenciado) aparece documentado en Lisboa. Siendo apoyado por la Reina Dña. Catarina de Austria por los monjes jerónimos, por el arzobispado de Évora y por los círculos de la corte portuguesa. Pinta retratos de su protectora y de D. João III en 1564 y tableros de retablos como el del monasterio de Vale Benfeito cerca de $1565-1570$ y de la capilla mayor de Santa Maria de Be-

${ }^{1}$ Los resultados de este trabajo de análisis histórico-artístico forman parte del libro de Carmen Olazabal Almada, Luís Tovar Figueira y Vitor Serrão História e Restauro da Pintura do Retábulo-Mor do Mosteiro dos Jerónimos, ed. IPPAR / Banco Comercial Português, Lisboa, 2000. Ahí consta una bibliografia actualizada del pintor Salzedo. Agradecemos al Prof. Fernando Bouza Álvarez (Universidad Complutense de Madrid) las preciosas referencias al retablo de Belém, que enriquecieron nuestras investigaciones.

${ }^{2}$ Caso de los pintores Juan y Diego de Salcedo, activos en Sevilla a finales del siglo xvi (Celestino López Martínez, Arquitectos, escultores y pintores vecinos de Sevilla, Sevilla, 1928, y Jesús M. Palomero Páramo, El retablo sevillano del Re nacimiento, Sevilla, 1983), del escultor Juan de Sauzedo, activo en Sevilla en 1534, del pintor homónimo activo en Granada en 1626, y del arquitecto Rodrigo de Saucedo activo en Córdoba en 1581 (P. Andrés Llordén, Escultores y entalladores malagueños, Avila, 1960, p.350) Alguno de ellos sería pariente de Lourenço de Salzedo?

${ }^{3}$ Sobre Vargas, cfr. Enrique Valdivieso, Historia de la Pintura Sevillana. Siglos xIII al xx, Sevilla, 1986; Juan Miguel Serrera, «Pintura y pintores del siglo xvı en la Catedral de Sevilla», La Catedral de Sevilla, Sevilla, 1985, pp. 353-404; y Jonathan Brown, La Edad de Oro de la pintura española, Nerea, Madrid, 1990, pp. 47-48; entre otras obras.

AEA, LXXVI, 2003, 303, pp. 249 a 265 

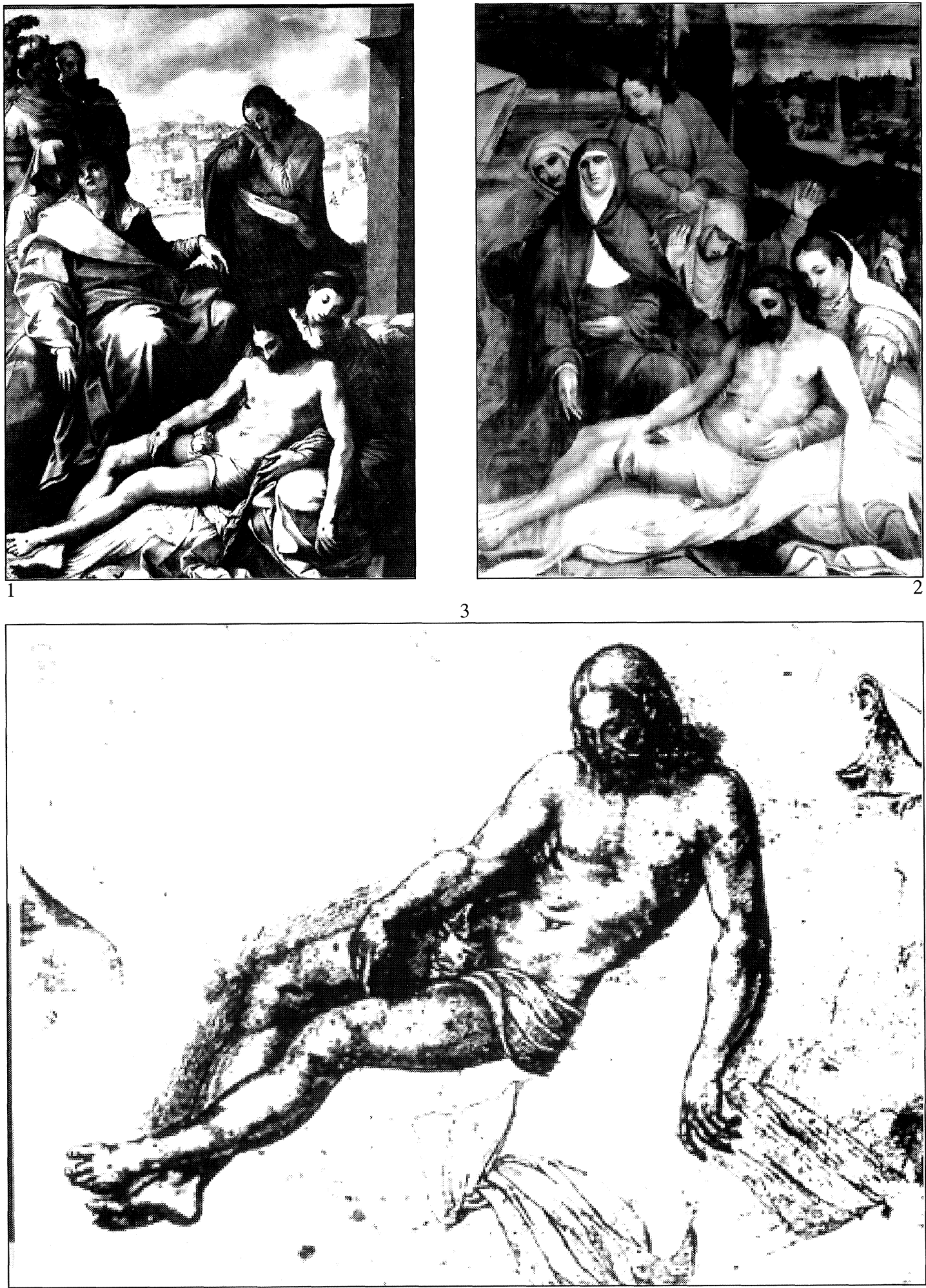

Fig. 1. Girolamo Siciolante da Sermoneta: Lamentación sobre el cuerpo de Cristo. 1542-1544. Retablo da Cappella MutiPaparuzzi nella iglesia dei SS. Apostoli de Roma, hoy en el Muzeum Narodowe de Poznan.

Fig. 2. Lourenço de Salzedo: Lamentación. Circa 1565. Evora, Museu de Arte Sacra de la Sé.

Fig. 3. Girolamo Siciolante da Sermoneta: Cristo Muerto (dibujo). Circa de 1542-1544. Windsor Castle, ${ }^{\circ} 928$. 
lém en 1570-72. Su prematuro fallecimiento en 1577, aún en ascenso de su carrera, coartó un recorrido que parecía destinado a un mayor éxito. Dentro de la generación de pintores portugueses (o aquí establecidos) en que Salzedo se integró, se encuentran los mayores nombres del Manierismo lusitano, como Gaspar Dias y António Campelo ${ }^{4}$, educados en Roma, el castellano Francisco Venegas y el extremeño Fernão Gomes, ambos pintores regios de Felipe II, y los lisboetas Diogo Teixeira, Simão Rodrigues y Amaro do Vale ${ }^{5}$.

El artista se instala en Lisboa alrededor de 1564 como pintor y retratista de la Reina. Es probable que su llegada se relacione con la solicitación de la propia Dña. Catarina, cuyo gusto romanista es conocido, sabiéndose que tal como la Infanta Dña. Maria, envió artistas a aprender pintura en Roma (son conocidas las cartas de 1560 relativas a los pintores António Leitão e João Baptista, por ejemplo), y que en la ciudad papal adquirió grabados, obras, e incluso tintas para óleo y fresco, siguiendo de cerca las novedades estéticas de la Bella Maniera. Salzedo puede haberse introducido en la corte portuguesa a través de estos círculos, en el momento en que por lo menos el pintor Antonio Campelo frecuentaba el círculo de Daniele da Volterra, bajo el mecenazgo del Cardenal Ricci de la Montepulciano, trabajando en las cámaras vaticanas de este protector (1552-1553). No obstante, no constan vestigios de la actividad de Salzedo en el ámbito de la Academia de San Lucas de Roma (aunque existan referencias a «pittori spagnuoli» que pueden estar dirigidas a él) ${ }^{6}$, y aún se ignora todo sobre su actividad antes de asentarse en Portugal.

Salzedo ya en 1564 está instalado en Lisboa. Casado con Jerónima de Salazar, vivió en casas en las Portas da Raínha, parroquia de Santos-o-Velho, y allí nacieron sus cuatro hijos. La última, Lourença de Monserrate ${ }^{7}$, fue bautizada el 15 de noviembre de 1577 ya después de su muerte prematura el 10 de julio de ese mismo año todavía a una edad temprana, siendo su testamentario el canónigo Afonso Gonçalves y siendo enterrado en el Monasterio de Nossa Senhora da Esperança, una de las fundaciones de la reina ${ }^{8}$. El reconocimiento que Dña. Catarina le profesaba se confirma en el testamento de la reina, en 1578, donde ésta se acuerda de «su pintor Salzedo», fallecido precozmente meses antes y por eso concede una especial autorización a la viuda para que pudiese sacar provecho de los privilegios y usufructos de ciertas propiedades de morada que habían sido del artista ${ }^{9}$.

De su obra (parte de la cual fue atribuida hasta fecha reciente, sin ninguna base de credibilidad, a Cristóvão Lopes, hijo del pintor renacentista Gregório Lopes), están identificadas las cinco grandes tablas de Santa Maria de Belém (1570-1572) (Fig. 4), cinco tableros del antiguo retablo del Convento de Vale Benfeito (c. 1570) (Fig. 7), ocho tablas de un retablo colateral en la Iglesia Mayor de Loures (Fig. 8), dos retratos de la Reina y otros dos de D. João III (póstumos, uno de ellos fechado en 1564, en el Museu Nacional de Arte Antiga (Figs. 5 y 6) y en el Monasterio da Madre de Deus, una Lamentación sobre el cuerpo de Cristo (c. 1565) en la Catedral de Évora (encomienda del Arzobispo D. João de Melo e Castro, que gobernó la archi-

\footnotetext{
${ }^{4}$ Vitor Serrão, «Il pittore portoghese Antonio Campelo y la Maniera italiana 1550-1580». Atti del Convegno Internazionale Pontormo e Rosso. La Maniera Moderna in Toscana,1494-1994, ed. Marsilio, Volterra-Empolí, 1996, pp. 185-188; idem, «La peinture maniériste portugaise, entre la Flandre et Rome, 1550-1620», Bolletino d'Arte, Supplemento al n 100 , 1997, pp. 263-276.

${ }^{5}$ Sobre estos artistas, cfr. V. Serrão (coord.), exposición A Pintura Maneirista em Portugal - arte no tempo de Camões, CNCDP. Lisboa, 1995.

${ }^{6}$ D. Martíñez de la Peña, «Artistas españoles en la Academia de San Lucas», A.E.A., XLI, 1968, n 163 , pp. $293-313$.

${ }^{7}$ Jorge de Moser, «Lourenço de Sauzedo, pintor da Rainha D. Catarina», Boletim do Museu Nacional de Arte Antiga, vol. II, $\mathrm{n}^{\circ} 1,1950$, pp. 27-31

${ }^{8}$ Idem, ibidem., p. 27: «(...) e assi sera usufructuaria em sua vida a viuva que ficou de Salzedo o pintor das casas em que pousava Dom Aleixo».

${ }^{9}$ Annemarie Jordan-Gschwend, The Development of Catherine of Austria's Collection in the Queen's Household: its character and cost, Brown University, 1993, introducción n. 11.
} 

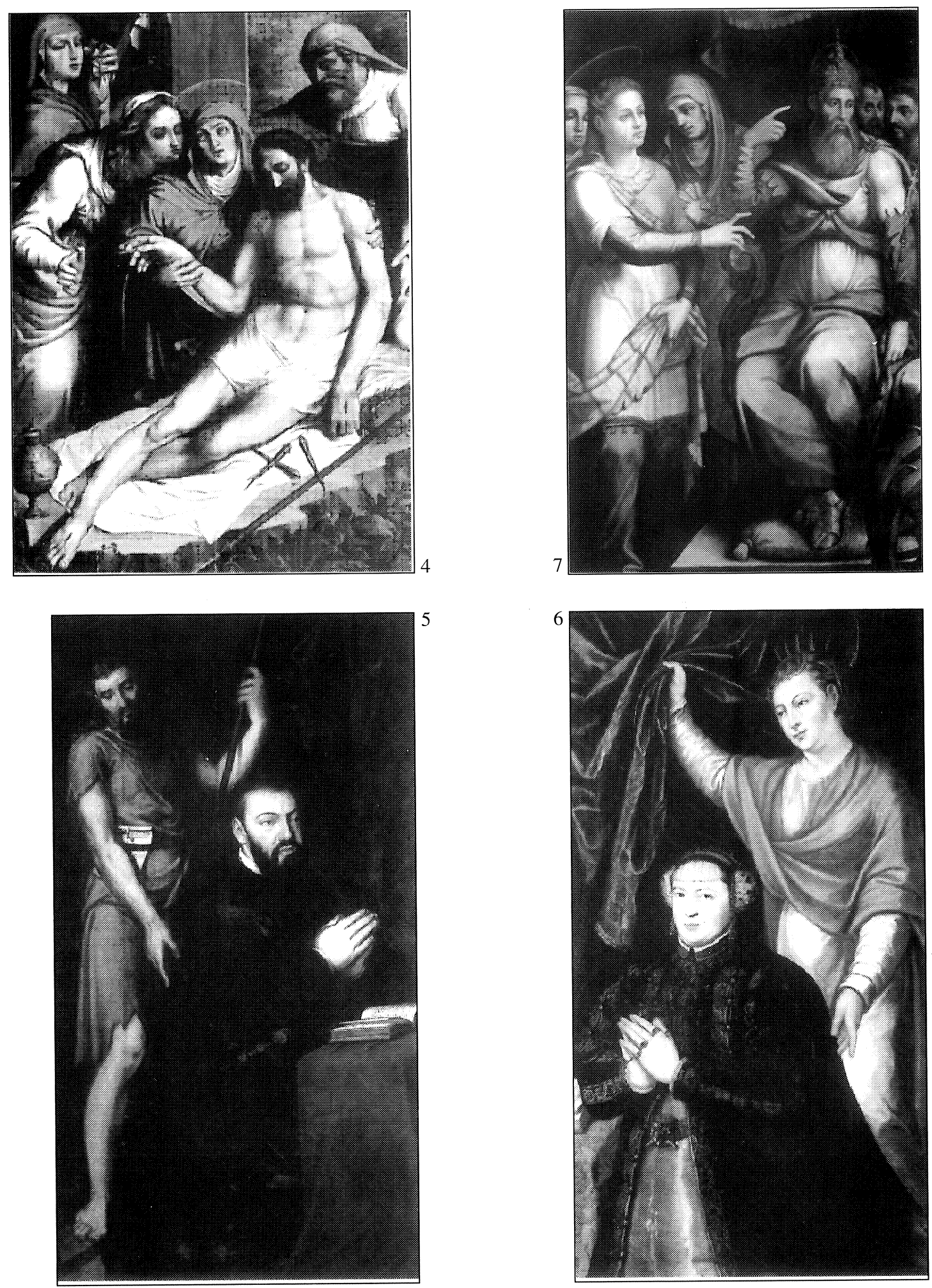

Fig. 4. Lourenço de Salzedo: Lamentación. 1570-1572. Lisboa, Monasterio de los Jerónimos

Figs. 5 y 6 . Lourenço de Salzedo: Retratos de D. João III y de D. Catarina com sus patronos San João Bautista e Santa Catalina. Circa 1572. Lisboa, Museu Nacional de Arte Antiga.

Fig. 7. Lourenço de Salzedo: Juicio de Santa Catalina. Circa 1565-1570. Misericórdia da Lourinhã. 
diócesis de 1564 a 1574) (Fig. 2), y una Virgen de la Leche en el Museo de Évora, además sabemos que dirigió una grandiosa decoración mural en la Iglesia del Hospital Real de Todosos-Santos. Fray Manuel Bautista de Castro llama al artista «el gran pintor Salzedo» ${ }^{10}$ porque en el tiempo en que escribe la Crónica del Monasterio de Santa Maria de Belém, estaba vivo el recuerdo de la obra del retablo, que había hecho furor en los medios artísticos de la Península. La reciente restauración de este retablo ha probado que al final Salzedo fue artista de amplios recursos, lo que confirma el aprecio que Dña Catarina le profesaba y que le impone un lugar destacado en el panorama de la pintura peninsular de su tiempo.

\section{Salzedo y Roma: un recorrido de seducciones plásticas}

El arte de la pintura producida en Roma en los años finales del papado de Paulo III (15341549) y en los del papado de Giulio III (1550-1555) constituye un momento de gloriosa autonomización de la Bella Maniera, que atrae a la ciudad de los papas las atenciones externas y justifica la presencia de tantos artistas oriundos de las más variadas partes, incluyendo la Península Ibérica ${ }^{10 a}$.

Bajo el estímulo de la bravura del dibujo, de la terribilitá miguelangelesca, de la grazia de las nuevas escenografías agitadas y de la libertad de las mezclas tonales, la pintura romana de estos años sorprende por la veracidad con que supera la anterior armonía del Renacimiento y repropone soluciones anticlásicas marcadas por la teatralidad de la composición y por la belleza grandiosa de los nuevos modelos. Obras tan importantes como la decoración de las cámaras papales de Paulo III Farnèse en el Castel de Sant'Angelo (donde Pierino del Vaga, Girolamo Siciolante, Pellegrino Tibaldi y Marco Pino, entre otros, actuan según dirección del primero), la decoración de las salas del Palazzo Ricci-Sacchetti (dirigida por el florentino Francesco Salviati), las célebres pinturas de las Capillas Sistina y Paolina en el Vaticano (por Miguel Ángel Buonarroti), los frescos y stuccos del Palazzo Capodiferro-Spada (donde a Daniele da Volterra y a Giulio Mazzoni se junta el español Becerra y, entre muchos otros, el escultor portugués Colmenares), las pinturas de las capillas de Trinitá dei Monti (donde Daniele da Volterra y sus colaboradores imponen su bravura y gigantismo de composición), los frescos de la Cappella Mattei en Santa Maria della Consolazione (por Taddeo Zuccari), sin olvidar el célebre programa afrescado del Oratorio de San Giovanni Decollato (demorosa empresa de Salviati, Jacopino del Conte y otros) y, aún, las facciate dipinte de la ciudad (de Polidoro da Caravaggio y sus colaboradores), recreadas tras el sacco de 1527, marcan el gusto refinado y revolucionario de la pintura romana en los años centrales del siglo XVI, que tanto influenció a jóvenes artistas oriundos de la Península como Gaspar Becerra ${ }^{11}$, Pablo de Céspedes ${ }^{12}$, Pedro

\footnotetext{
${ }^{10}$ Frei Manuel Bautista de Castro, Cronica do Maximo Doutor e Principe dos Patriarcas São Jeronimo, particular do reyno de Portugal, dedicado a D. João V, Arquivos Nacionais/Torre do Tombo, mss. $\mathrm{n}^{\circ} 270,1^{\mathrm{a}}$ parte.

$10^{\circ}$ Sobre este ambiente artístico, cfr. Giuliano Briganti, La Maniera Italiana,ed. Sanzoni Editori, Florença, 1985, pp. 5760; André Chastel, La crise de la Renaissance,1520-1600, Skira, Genéve, 1968; Maria Cali, Da Michelangelo all Escorial. Momenti del dibattito religioso nell'arte del Cinquecento, ed. Einaudi, Torino, 1980; Teresa Pugliatti, Giulio Mazzoni e la decorazione a Roma nella cerchia di Daniela da Volterra, Roma, 1984; Antonio Pinelli, La Bella Maniera. Artisti del Cinquecento tra regola e licenza, ed. Einadi, Turim, 1993, pp. 71-85; Elena Parma Armani, Perin del Vaga. L'annello mancante. Studi sul Manierismo, Sagep ed., 1996; Janet Cox-Rearick, «Francesco Salviati et la Bella Maniera», exposición Francesco Salviati ou la Bella Maniera, Louvre, 1998, pp. 25-30; y Alfonso E. Pérez Sánchez ed alii, Los Frescos Italianos de El Escorial, Electa, Madrid, 1993.

"Sobre Becerra, que más adelante reencontraremos citado al respecto del retablo de Belém, cfr. Gonzalo Redín Michaus, «Sobre Gaspar Becerra en Roma. La Capilla de Constantino del Castillo en la iglesia de Santiago de los Españoles», A.E.A. LXXV, 2002, n 298, pp. 129-144.

${ }^{12}$ Sobre Céspedes, cfr. Antonio Urquijar Herrera, El Renacimiento en la periferia... La recepción de los modos italianos en la experiencia pictórica del Quinientos cordobés, Universidad de Córdoba, 2001.
}

AEA, LXXVI, 2003, 303, pp. 249 a 265 
Roviale, Salzedo y Campelo, y otros que, desde Italia, se instalaron después en tierras de España difundiendo ese gusto, como Pietro Morone de Piacenza ${ }^{13}$ en Tarazona, el florentino Benito Rabuyate ${ }^{14}$ en Valladolid, y el muy 'polidoresco' Tomas Peliguet en Zaragoza ${ }^{15}$, más o menos influenciados todos ellos por el ámbito artístico del que Maria Calí ha denominado «escuela de Trinitá dei Monti».

Figura particularmente interesante en la Roma de entonces, que congregaba influencias seguidas por los artistas pensinsulares citados y era asumidamente una de las estrellas de la nueva constelación de pintores romanos fue Girolamo Siciolante da Sermoneta (1521-1575), considerado el más apto de los discípulos de Pierino del Vaga y que tuvo el cúlmen de su carrera (después de un periodo al servicio de los Farnèse) en la Roma de Giulio III, cuando llega a cónsul de la Academia de San Lucas (1554) y pinta en Santa María sopra Minerva, en Santa María in Anima y San Giacomo degli Spagnuoli. Su pintura de la Lamentación sobre el cuerpo de Cristo (Fig. 1), ejecutada en 1542-1544 para el altar de la Cappella Muti-Paparuzzi en la Iglesia dei Santi Apostoli de Roma (hoy en el Muzeum Narodowe, de Poznan) ${ }^{16}$, es una pieza muy importante, pues nos muestra claramente los contornos de la educación romana y los referentes plásticos seguidos por Lourenço de Salzedo en sus años de Roma. Si éste tuvo entonces contactos con la comunidad portuguesa asentada en la Ciudad Papal se ignora, pero recordemos que Campelo se movía entonces, tal como Becerra, en el círculo de los mismos artistas miguelangelescos, entre ellos, los pintores Daniele da Volterra y Girolamo Siciolante, el maestro de stucco Giulio Mazzoni, el escultor Leonardo Sormani; forzosamente habría relaciones, contactos e intercambio de información en el círculo de estos artistas. La pintura de Siciolante en la capilla Muti-Paparuzzi, que tanto influenció a Salzedo, es una bellísima pieza de fuerte idealización pierinesca (con ecos también de la Deposición de Sebastiano del Piombo en Santa Maria sopra Minerva) y que mereció expreso elogio de Giorgio Vasari en la 2. ${ }^{a}$ edición de las Vite ${ }^{17}$. La composición fue seguida fielmente por Salzedo en una pintura que ejecutó veinte años después para la Catedral de Évora (Fig. 2), encargo del Arzobispo D. João de Melo e Castro. No sólo la construcción de esa Lamentación hoy en Poznan es fielmente seguida en el tablero de Évora, sino también el cuidadoso dibujo de las carnes, de los tejidos y de los accesorios que refleja la influencia de la grazia pierinesca (recordando en la figura de la Virgen María, por ejemplo, la misma figura pintada por Pierino en la Resurrección de Lázaro del Victoria and Albert Museum de Londres), y también la atmósfera escenográfica que envuelve al grupo de Cristo y de las Santas Mujeres, con sus tonos rosas, verdes, azules y amarillos vivos y el fondo exótico con referentes paganizados (entre ellos un obelisco, una pirámide y un templo centralizado, tópicos que del mismo modo reutilizó, integrando figuras de elefantes, en un fondo de la Adoración de los Reyes Magos de Santa Maria de Belém). Todo esto atestigua una atentísima y pormenorizada observación de Salzedo para la tabla Muti-Paparuzzi, que sólo podría hacerse de visu y que define el contexto preciso de su formación romana.

\footnotetext{
${ }^{13}$ Sobre Morone, cfr. Lucía Varela Merino, «La venida a España de Pietro Morone y Pietro Paolo de Montalbergo: las pinturas de la capilla de Luis de Lucena, en Guadalajara», Boletin del Museo e Instituto Camón Aznar, vol. LXXXIV, 2001, pp. $175-184$.

${ }^{14}$ Sobre Rabuyate, cfr. Manuel Arias Martínez, «El testamento de Benedito Rabuyate, un pintor florentino en el Valladolid de la segunda mitad del siglo XVI. Devociones y producción artística», Valladolid. La muy noble villa, exp., Valladolid, 1996, pp. 41-47.

${ }^{15}$ Jesús Criado Mainar, «Tradición y renovación en los usos profesionales de los talleres pictóricos zaragozanos del Pleno Renacimiento», Boletín del Museo e Instituto Camón Aznar, L, 1992, pp. 5-83; idem, Las Artes Plásticas del Segundo Renacimiento en Aragón. Pintura y Escultura, 1540-1580, Tarazona, 1996.

${ }^{16}$ Cfr. John Hunter, Teresa Pugliatti y Luigi Fiorani, Girolamo Siciolante da Sermoneta (1521-1575). Storia e Critica, Roma, 1983, p. 23 e est. 3, e John Hunter, Girolamo Siciolante, pittore da Sermoneta, 1521-1575, Fundazione Camillo Caetani, Roma, 1996, pp. 26-28 y 127-131.

${ }^{17}$ Giorgio Vasari, Vite (...), vol. V, ed. 1880, pp. 629-630.
} 
El hecho de que esta tabla de Girolamo Siciolante nunca haya sido pasada a grabado (aunque existan dos dibujos preparatorios de la autoría de Siciolante, en el Windsor Castle, con los n. ${ }^{\text {os }}$ de inv. ${ }^{\circ} 456$ e 928) (Fig. 3) prueba la atención con que Salzedo la admiró y de ella sacó el «ejemplo» esencial para el cuadro de Évora. Sólo ese hecho revelaría el paso de Salzedo por la Ciudad Papal y la atención con que vio obras del mejor discípulo de Pierino. Además en otras pinturas de Salzedo con la escena de la Lamentación sobre el cuerpo de Cristo -la del retablo mayor de Santa Maria de Belém (Fig. 4) y la de la iglesia mayor de Atouguia da Baleia, de composición más simplificada, que procede del antiguo retablo del Monasterio del Vale Benfeito- el modelo del Cristo muerto junto a la Virgen y las Santas Mujeres retoma precisamente el mismo modelo de Girolamo Siciolante en la pala Muti-Paparuzzi. También en una obra de Vargas, la Lamentación sobre el cuerpo de Cristo de la iglesia de Santa María la Blanca de Sevilla, se revelan algunas coincidencias de modelo, que son evidentes confrontándolas con la tabla central de Belém y la tabla de Évora. El sensual modelo de María Magdalena, que en el cuadro de Évora es osadamente tratado sin velo en la cabeza, con sus ropas de golilla bordada y mangas amarillas que contrastan sobre el corpiño verde, retoma con variaciones el del cuadro de la iglesia de los Santi Apostoli, aduciendo libertades en la caracterización de la figura a partir del modelo pierinesco. La figura de Santa Catalina de Alejandría en los dos retratos de la Reina (M.N.A.A. y Monasterio de Madre de Deus) remite para el conocimiento del fresco de Santa Lúcia y Santa Agata del Sermoneta nella Basilica di Santa Maria Sopra Minerva en Roma (Figs. 11 y 12). Por fin, en las pinturas del altar de la iglesia mayor de Loures, también los fondos imaginarios pintados por Salzedo, nostalgicamente iluminados e impregnados de referencias all antico, denotan la misma derivación romana de modelos de Sermoneta y de Sebastiano del Piombo (Capella Chigi en Santa Maria del Popolo) (Figs. 13 y 14), del ambiente general del Manierismo romano en los años centrales del siglo XVI.

En todas las obras citadas, Lourenço de Salzedo refleja una esmerada educación romana: dibuja con sensibilidad, en finas veladuras, compone con profundo sentido de la elegancia formal y expresividad escenográfica (en lo que recuerda no sólo a Pierino, Daniele y Siciolante sino también al refinamiento del florentino Francesco Salviati y, en cierta medida, a la grande maniera fresquista de Giorgio Vasari en el Palazzo Vecchio de Florencia y en el Palazzo della Cancelleria de Roma), pinta con trasparencia de colores vivos y mezclados, explora la argucia de la tensión manierista, juega irónicamente con la bizarria de los ejemplos salidos de un repertorio vivo y provocador, crea recetas personales de modelos y poses, explora aspectos de la sensualidad e incluso del erotismo (véase a Santa María Magdalena arrepetdida del retablo de Loures) (Fig. 8), desarrolla una escala temeraria y monumental, y hace resaltar de los valores plásticos un sentido de escultura viva que resalta en la contemplación de sus pinturas. Las poses elegantes y robustas de los patronos regios, en los dos pares de retratos de Dña Catarina y de D. João III (póstumo, según modelo de Moro), testifican el mismo estilo romano, secuaz de modelos buonarrotiescos como los de la Cappella Paolina y de Sermoneta en Santa Maria sopra Minerva. Ciertas figuras de soldados en el retablo de Belém y otros personajes en el Juicio de Santa Catalina de Vale Benfeito (hoy en la Misericórdia da Lourinhã) (Fig. 7), recuerdan mucho a los modelos del último plano de la Lamentación Muti-Paperuzzi de Siciolante (que la versión de Salzedo en Évora no retomó). Después, hay en la textura pictórica de los cuadros de Salzedo una sensualidad y una finura que tiene la grazia pierinesca y de nuevo, remite para ejemplos de la pintura romana en los años centrales del siglo XVI.

El cuidado puesto por Salzedo en una escenografía de escala monumental y en una tipología de pose de estilo miguelangelesco, completamente inesperada en el panorama nacional de la época, acentúa la importancia del artista en el panorama peninsular de su tiempo - como debe ser en adelante reconocido- y, en el caso de las tablas de Santa Maria de Belém, nivela

AEA, LXXVI, 2003, 303, pp. 249 a 265 

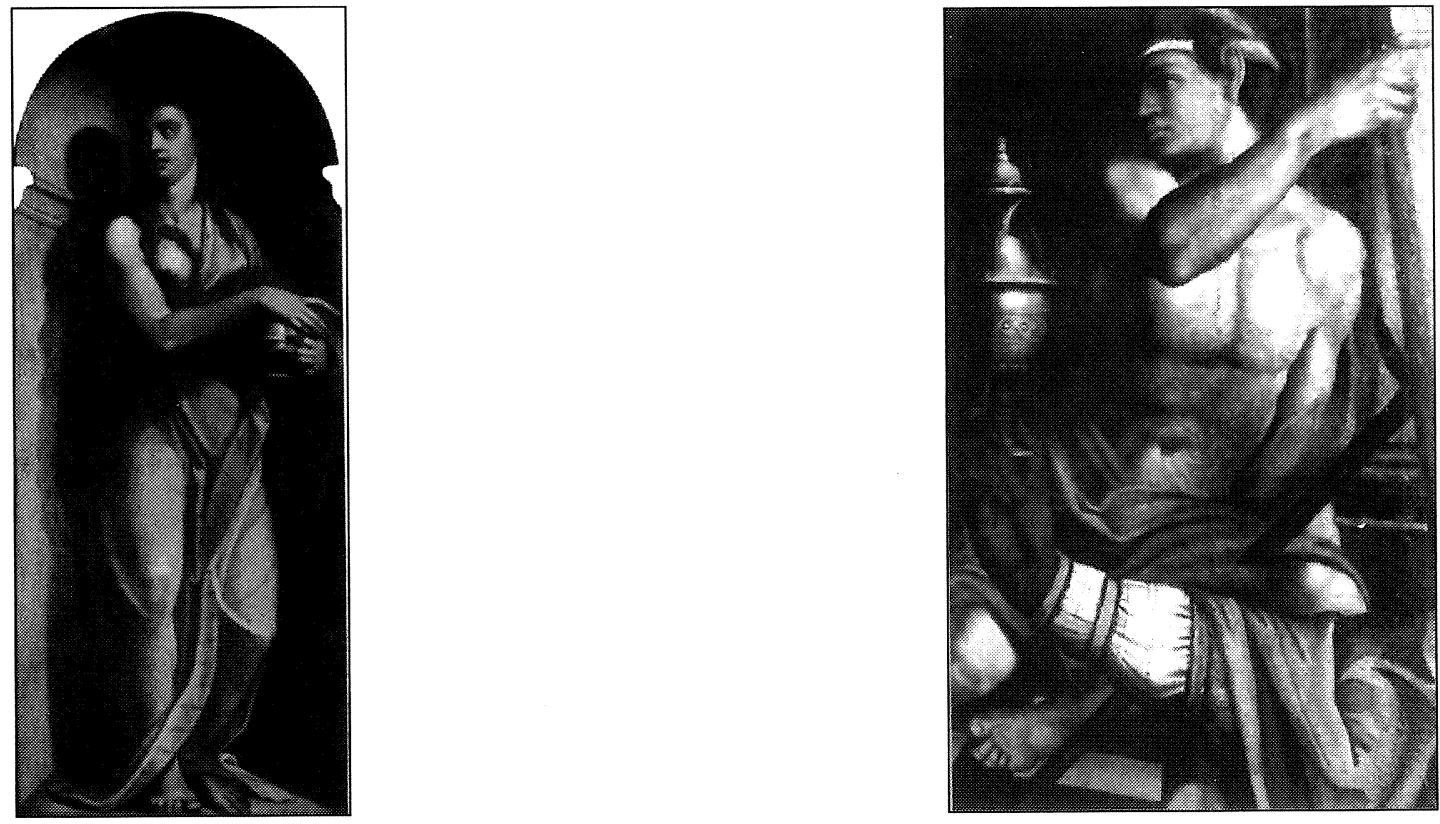

8

9

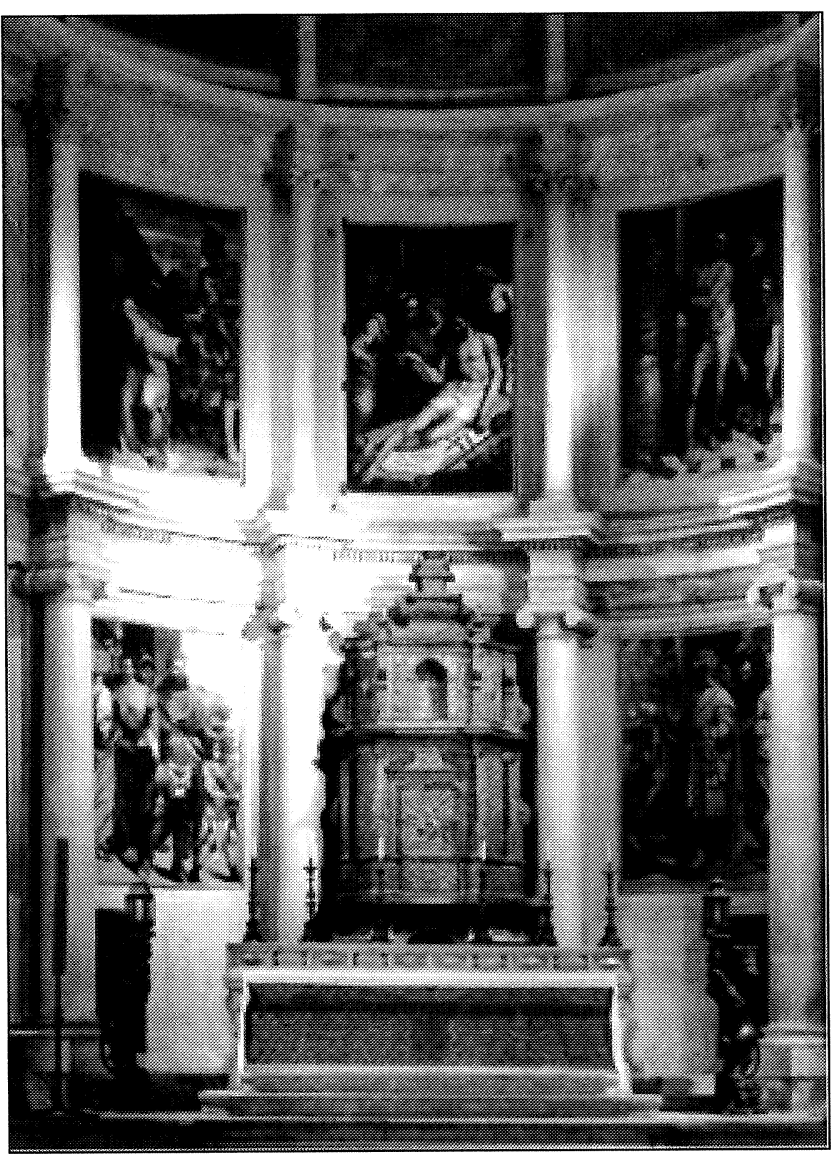

Fig. 8. Lourenço de Salzedo: Santa María Magdalena. Circa 1565-1570. Iglesia Matriz de Loures.

Figs. 9 y 10. Jerónimo de Ruão (arquitectura) e Lourenço de Salzedo (pintura): Capela mayor del Monasterio de los Jerónimos. 1570-1572. Conjunto del Retablo y detalle de la Adoración de los Reyes.

$A E A$, LXXVI, 2003, 303, pp. 249 a 265 
el pintor con las cualidades extraordinarias de la fábrica arquitectónica de la capilla-panteón realizada por Jerónimo de Ruão (hoy reconocida por la historiografia del arte como una obra excepcional), probándose que el programa costeado por Dña. Catarina buscaba incluso acentuar el aggiornamento con el Manierismo italiano en todos sus aspectos formales y escenográficos.

Con la empresa del retablo de los Jerónimos de Lisboa, Salzedo abre camino a la tradición de la bella maniera italiana en los encargos cortesanos del último tercio del siglo XVI, e influencia de manera relevante a otro pintor andaluz establecido en Lisboa, Francisco Venegas, que en realidad sólo destaca como gran pintor de la corte después de 1580, o sea, después de la muerte de Salzedo , lo que no puede dejar de ser significativo. En adelante, tiene que pensarse en Lourenço de Salzedo, no como un mero «epígono sin llama» de una corriente romanista ya establecida en Portugal en 1570, sino como uno de sus más exaltados introductores.

\section{La historia del retablo del Monasterio de los Jerónimos}

La documentación que hoy se conoce permite reconstruir los pasos esenciales de la costosa empresa de la capilla-panteón de Santa Maria de Belém. Estando en 1568 las obras de cantería de la capilla mayor de Santa Maria de Belém en fase terminal, bajo la dirección de su autor, el arquitecto Jerónimo de Ruão, empezaron las diligencias de la reina viuda Dña. Catarina para decorarla con grandes pinturas destinadas (como desde pronto decidieron los autores del programa) a integrar la estructura pétrea del recinto, en lugar del tradicional retablo de madera. Al satisfacer a Dña. Catarina estas pinturas entre 1570-1572, Salzedo siguió con plena fidelidad el Maneirismo romano, el estilo por el que se decantaban los frailes jerónimos en varias decoraciones, tanto en el coro (con las esculturas de la sillería, por Diogo de Çarça y Filipe de Vries, 1550-1552, y la escultura de Cristo, del último, obras bien estudiadas por Nicole Dacos y Diogo Corrêa ${ }^{18}$ ), como en los bajo relieves de la nave transversal (piezas en scicciato italiano de autor desconocido), como también en los altares del claustro (confiados a Campelo y Gaspar Dias), en la extraordinaria decoración pétrea de la platabanda del claustro (c. 1542-1548, dirigida por Diogo de Torralva, con tondi, trofeos, cascos alados, centauros de frente y grottesche) y en el originalísimo «trazo» miguelangelesco de la capilla mayor, obra del arquitecto Jerónimo de Ruão, que tantas expectativas creó a Felipe II, hasta el punto de solicitar éste a sus agentes en Lisboa un fiel dibujo de la traza. El triunfo de la bella maniera en los programas de Santa Maria de Belém en tiempos de Dña Catarina, muestra un sentido de internacionalización y en los términos precisos de la época, la búsqueda de un buen gusto, el ardor manierista que se manifiesta al unísono con los pasos de un absolutismo ibérico centrado en la figura de la reina Dña Catarina.

Las pinturas - realizadas en madera de roble e integradas en los edículos de la estructura marmórea de las capillas- representan, en el piso superior a Cristo con la cruz a cuestas $(3.200 \times 2.050 \mathrm{~mm})$, Lamentación sobre el cuerpo de Cristo $(3.200 \times 2.050 \mathrm{~mm})$ (Fig. 4) y Flagelación de Cristo $(3.200 \times 2.050 \mathrm{~mm}) \mathrm{y}$, abajo, la tripartita Adoración de los Reyes $(3.200$ $\times 2.130 \mathrm{~mm}$ cada uno, habiéndose perdido la parte central de la Epifanía). Su historia está documentalmente aclarada. Como hoy se sabe, Dña Catarina discutió desde 1568 el modelo a seguir: se debía optar por una pintura «incorruptible», esto es, ejecutada sobre la piedra negra de Génova que forma los edículos - como entonces se hacía en Italia con el ejemplo mayor de

\footnotetext{
${ }^{18}$ Diogo Maleitas Corrêa, O Cadeiral do Mosteiro dos Jerónimos, entre o Humanismo e a Contra-Reforma, Faculdade de Letras da Universidade de Lisboa, 2002.
}

AEA, LXXVI, 2003, 303, pp. 249 a 265 
Sebastiano del Piombo- o con paneles a óleo sobre tablas de roble. Cuestiones climatológicas ligadas al sitio de Belém llevaron a los consejeros dela reina a defender una pintura «eterna de viveza», compuesta sobre la piedra de los edículos de la capilla, pero la segunda hipótesis acabó por prevalecer. La Reina Dña Catarina de Austria estimaba (a pesar de lo que sobre eso se ha dicho) el noble arte de la Pintura: encargó retratos de la corte al célebre Anthonis Moro en 1552, a Francisco de Holanda en 1554, al flamenco Joozis van der Straeten (Jorge de Estrada) en 1556, y a Cristóvão de Morais, en $1571^{19}$; poseía una galería de retratos de poderosos del tiempo y, tal como Rodolofo II en Praga, reunió una gallerietta de piezas extravagantes; se relacionaba con su sobrino Felipe II en negocios artísticos y habrá aconsejado a D. Sebastião a redactar el decreto de desvinculación de los pintores de óleo de Lisboa de los deberes de la Bandeira de São Jorge ${ }^{20}$; finalmente ordenó a su pintor Salzedo obras importantes, como el retablo del monasterio jerónimo de Vale Benfeito ${ }^{21}$. Era una princesa de extrema cultura, que desde la viudedad había tomado el encargo de erigir la capilla-panteón de Belém dentro de los más evolucionados cánones estéticos del momento. El proyecto, que costeó con sus posesiones (y que hizo erguir contra la voluntad de D. Sebastião) es una de las obras primas de la arquitectura manierista europea y será elogiado por D. Juan de Borja, embajador español en Lisboa, como «capilla de admirable piedra colorado, pardo, verde y blanco y de columnas de marmol blanco, y el suelo de piedras de las mismas colores com quatro sepulturas puesta cada una sobre dos elephantes», y con «un muy grande retablo y vidrieras que mandó traer de Venecia para las ventanas de vidrio christalino» ${ }^{22}$.

Su deseo de internacionalizar el programa de la capilla la llevó a aspirar a recursos alternativos para la obra de la pintura ${ }^{23}$. En enero de 1568 hacía diligencias en la corte de Madrid junto a su sobrino Felipe II para que éste la ayudase a escoger quien pintase los paneles directamente sobre la piedra genovesa de los edículos, que «coge muy bien la pintura», esto es, una «pintura perenne». El 3 de febrero de 1568, discutía con el embajador D. Francisco Pereira la manera de hacer el retablo, si con paneles ejecutados sobre la piedra negra, o sobre madera de roble del Norte, siendo aquélla hipótesis preferible para hacer de los cuadros a pintar «incorruptibles». Se decidió por el famoso pintor flamenco Franz Floris (lo que induce a creer que los portugueses fueron de antemano excluidos), pero la reina pretendió tener el aval de su sobrino, reconocida autoridad en la materia. Es probable que también su hermana María de Hungría fuese considerada en la elección del pintor, siendo conocida la atención con que Dña Catarina seguía sus opiniones. Felipe II sugiere como alternativa a Floris un artista de educación romana muy estimado por él, el pintor y escultor Gaspar Becerra ${ }^{24}$, que se había distinguido

${ }^{19}$ Annemarie Jordan, Retrato de Corte em Portugal. O Legado de António Moro, Quetzal, Lisboa, 1994, pp. 146-150 y 179-184. Los dobles retratos de D. João III y de Dña. Catarina por Salzedo aún continúan en esta obra erróneamente atribuidos al pintor Cristóvão Lopes.

${ }^{20} \mathrm{Cfr}$. Vitor Serrão, O Maneirismo e o estatuto social dos pintores portugueses, Lisboa, 1983.

${ }^{21}$ En el demolido monasterio de Vale Benfeito (Óbidos), la reina ordenó diversas obras además del retablo pintado por Salzedo (cfr. V. Serrão, A Pintura Maneirista em Portugal, Lisboa, 1982, pp. 58-59), donó muchos bienes y piezas sacras a esa casa de frailes jeronimos (Annemarie Jordan-Gschwend, «Catherine of Austria and a Habsburg Relic for the Monastery of Valbenfeito, Óbidos», Journal of the History of Collections, $\mathrm{n}^{\circ} 2,1990$, pp. 187-198).

${ }^{22}$ Sylvie Deswarte, «Francisco de Holanda e o Mosteiro de Santa Maria de Belém», Jerónimos - quatro séculos de pintura, exposição, 1994, p. 57.

${ }^{23}$ Cfr. la importantísima documentación publicada a este respecto en el libro de Carmen Olazabal Almada, Luís Figueira e Vitor Serrão História e Restauro da Pintura do Retábulo-Mor do Mosteiro dos Jerónimos, ed. IPPAR / Banco Comercial Português, Lisboa, 2000. De nuevo agradecemos al historiador Fernando Bouza Alvares la indicación de pistas de investigación archivísticas que se revelaron esenciales en esta materia.

${ }^{24}$ Sobre la figura y obra de Becerra, cfr. Jonathan Brown, La Edad de Oro de la Pintura en España, Nerea, Madrid, 1990, pp. 56-57; A. Barrón e M. P. Ruiz de la Cuesta, «Notas sobre el retablo de Santa Clara de Briviesca», A.E.A., 1997, $\mathrm{n}^{\circ}$ 279, pp. 255-269; e Gonzalo Redín Michaus, «Sobre Gaspar Becerra en Roma. La Capilla de Constantino del Castillo en la iglesia de Santiago de los Españoles», cit.

AEA, LXXVI, 2003, 303, pp. 249 a 265 
en innumerables intervenciones oficiales por el vigoroso tono miguelangelesco, después de haber frecuentado los círculos de Miguel Ángel y de Giorgio Vasari, hecho frescos en una capilla en Santiago de los Españoles de Roma en 1553 y de llegar a ser discípulo de Daniele da Volterra. Después de regresar a España, en 1557, fue autor de obras tan célebres como el retablo de la Catedral de Astorga y los frescos del palacio del Pardo con la Historia de Perseo. El retablo de la iglesia del Monasterio de las Descalzas Reales de Madrid, obra de Becerra, llega a ser referido en este intercambio de correspondencia con Dña. Catarina de Austria, pues el embajador se compromete a ir a obtener una traza de ese retablo para enviárselo a la reina. Becerra era una celebridad: había llegado al extremo, dice el tratadista Francisco Pacheco en el Arte de la Pintura (1649), de «quitar a Berruguete gran parte de la gloria que había adquirido (...), por haber seguido a Miguel Ángel, y ser sus figuras más enteras, y de maior grandeza». Simplemente, Becerra cayó enfermo cuando estas diligencias se procesaban, y falleció prematuramente el 23 de enero de 1568, a pocas semanas de la fecha en que la carta de D. Francisco Pereira era redactada. Era por tanto, una posibilidad radicalmente eliminada.

En cuanto al nombre en que Dña. Catarina insiste, Franz Floris de Vriendt (nace en 1519, permanece en Roma entre 1541-1545, y muere en Amberes en 1570), será Felipe quien se lo desaconseja a la reina, poniendo en duda su «catolicismo», convirtiéndose en una razón suficiente para su exclusión. Floris había sido discípulo de Lambert Lombard en Liège y, después, estudió en Roma la maniera de los seguidores de Rafael (Polidoro da Caravaggio, Giulio Romano y Francesco Salviati). Fue maestro de Anthonis Blocklandt de Delft, que deja en Portugal una Incredulidad de Santo Tomás (M.N.A.A., inv. ${ }^{\circ}$ 377), con «fuertes entonaciones a la manera de Floris», según Nicole Dacos ${ }^{25}$. Los términos de una de las cartas del embajador a la reina revelan que Felipe II reaccionó con falta de entusiasmo al nombre sugerido por Dña. Catarina, por constar que Floris «no andaba bien en los negocios de la religión». Del resto, su muerte prematura impidió que se pudiese pensar en una eventual invitación a Lisboa. La reina tuvo que buscar alternativas: el tercer nombre que se invoca en este intercambio de correspondencia es Francesco da Urbino (o Francisco de Urbina, en la fórmula castellanizada), pintor urbinense de formación genovesa, que llega a Madrid a finales de 1567 o inicios de 1568 como especialista en la modalidad de fresco, junto a su hermano Giovanni Maria da Urbino, con Rómulo Cincinnato (un celebrado discípulo de Salviati), Francesco Granello y Fabrizio Castello, por llamamiento de su maestro Giovan Battista Castello, o Bergamasco (a quien sustituyó por muerte de éste en 1569, en la dirección de las obras del Palacio del Alcázar y del Monasterio del Escorial). Considerado por Pierluigi Carofano «una de las figuras más enigmáticas de la legión de artistas italianos al servicio de Felipe II», pintó algunas decoraciones con finos ornatos de grotesco romano en el Monasterio del Escorial (Sala de Teología, Celda del Gran Prior y otros espacios), en el Palacio del Alcázar, en el Palacio Real de Valsaín y en la Casa del Bosque de Segovia, y murió en Madrid aún joven en diciembre de $1582{ }^{26}$. Francisco de Urbino no vendría a Lisboa porque ulteriores indagaciones sobre su merecimiento llevan a Felipe II a replantear la indicación dada al embajador portugués. Las escenas historiadas que dejó hechas en el Escorial (grutescos, falsos estucos, bajo relieves simulados, figuras de «hermes», el fresco del Juicio de Salomón (1581) que decora la cela baja del Grão-Prior, etc.) muestran un estilo elegante inspirado en la maniera florentina, con figuras bien trazadas y amplios escenarios provistos de arquitecturas clásicas, lo que llevaría al cronista Fray José de

\footnotetext{
${ }^{25}$ Nicole Dacos, «Incredulidade de São Tomé», in A Pintura Maneirista em Portugal - arte no tempo de Camões, coord. de V. Serrão, CNCDP. Lisboa, 1995, pp. 244-247.

${ }^{26}$ Cfr. Fernando Checa Felipe II Mecenas de las Artes, ed. Nerea, Madrid, 1992, Rosa López Torrijos, «Francisco de Urbino», Reales Sitios, 1998, e Pierluigi Carofano, «Francesco da Urbino y la decoración de la celda baja del prior», Los Frescos Italianos de El Escorial, ed. Electa, Madrid, 1993, pp. 99-119.
} 


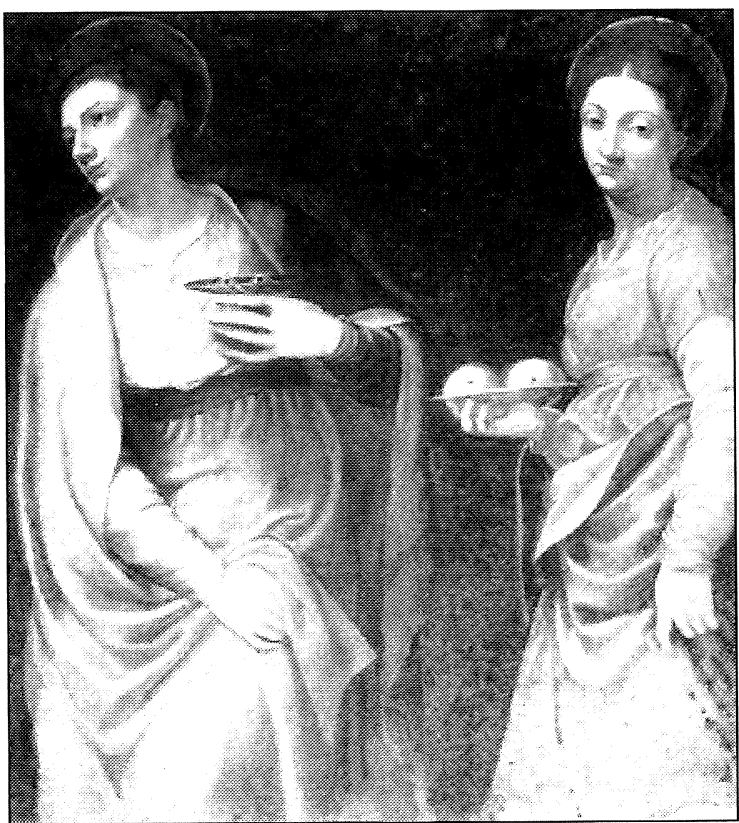

11

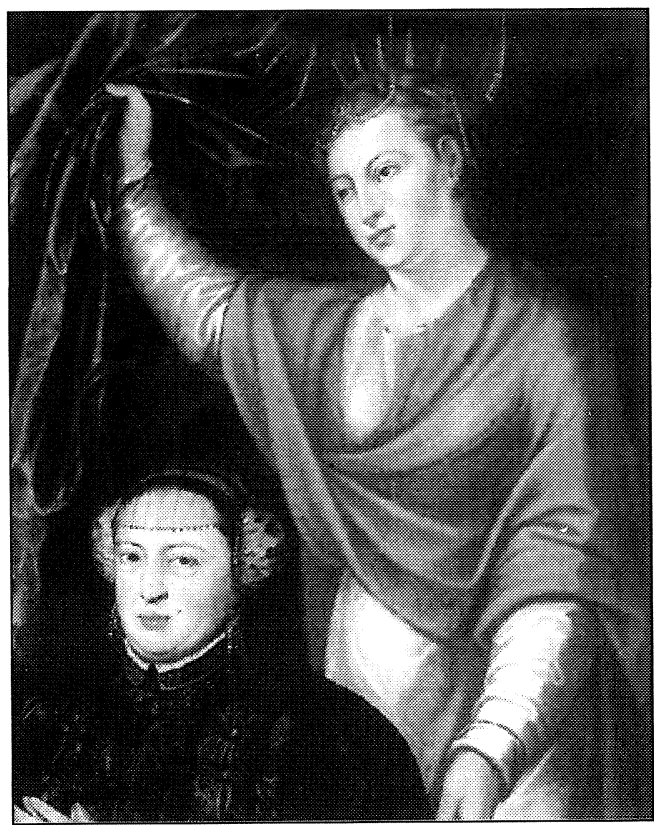

12

13
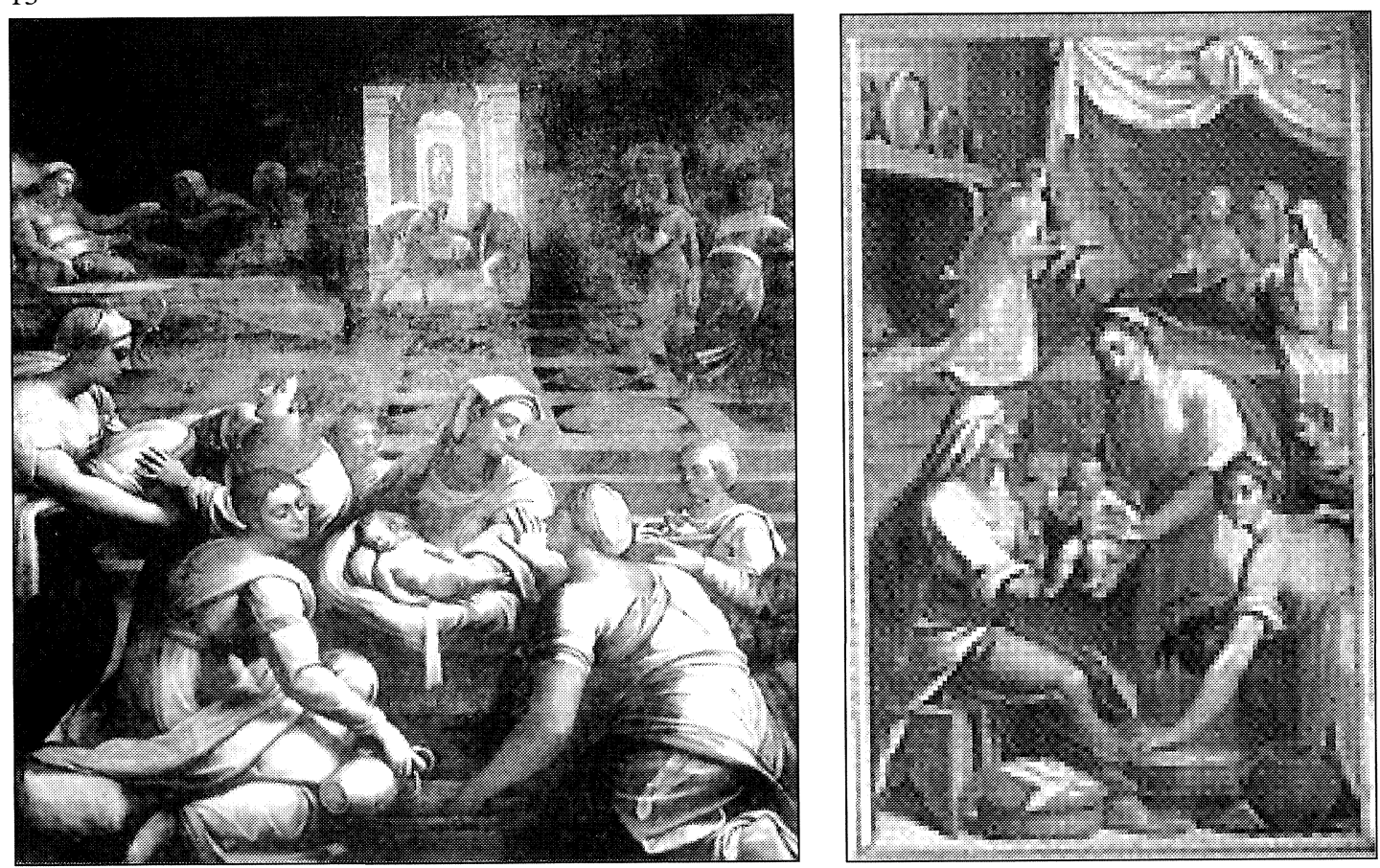

14

Fig. 11. Girolamo Siciolante da Sermoneta: Santa Lucía y Santa Águeda. Circa 1550. Roma, iglesia de Santa María Sopra Minerva.

Fig. 12. Lourenço de Salzedo: Retrato de D. Catarina con su patrona Santa Catalina. Detalle. Circa 1570. Lisboa, Museu Nacional de Arte Antiga.

Fig. 13. Sebastiano del Piombo (y Francesco Salviati): Nacimiento de la Virgen. Detalle. C. 1547. Roma, Santa Maria del Popolo, Cappella Chigi.

Fig. 14. Lourenço de Salzedo: Nacimiento de la Virgen. Circa 1565-1570. Iglesia Matriz de Loures.

AEA, LXXVI, 2003, 303, pp. 249 a 265 
Sigüenza (1605) a definirlo como «artista malogrado», no sólo por la brevedad de la estancia madrileña sino también por su prometedora capacidad ante los otros italianos que le siguieron el rastro y llegan a Madrid para intervenir en las obras del Escorial cerca de 1585 (Federico Zuccari, Pellegrino Tibaldi, Patricio Caxès y otros; Luca Cambiaso había llegado poco antes) ${ }^{27}$. La autoridades portuguesas optaron por abandonar el proyecto de hacer en Belém pintura sobre piedra, especialidad en que Urbino ni siquiera estaba habilitado, como las misivas dan a entender. La verdad es que los pintores que Dña Catarina tenía a su disposición en la corte (Campelo, Gaspar Dias, Salzedo) superaban el currículo artístico del muralista italiano, y Francisco de Urbino acabó por no venir.

Frustradas estas diligencias, la reina Dña Catarina se dirigió al mercado interno, que ofrecía garantías para componer la obra de Belém con la modernidad requerida y escoge a Salzedo para pintar las tablas de la capilla mayor. Con la elección del pintor (que el cronista jerónimo Frei Manuel Baptista de Castro elogia llamándole «el gran pintor Salzedo» ${ }^{28}$ ), la obra transcurre con rapidez: en julio de 1571 las tablas estaban avanzadas, pues se conocen diligencias para comprar en Roma, a través del embajador D. João Telo de Meneses, las pinturas requeridas por el pintor, que debían ser enviadas por mar, menos el raro «azul ultramarino» que, por ser pigmento esencial para la obra, se pedía de urgencia por el primer correo. Recordamos que ya en enero de 1539 Dña Catarina había ordenado a Baltazar de Faria, embajador en Roma, que adquiriese tintas, pigmentos y pinceles para pintar a óleo, fresco e iluminados, incluyendo "oleo de piedra mui fino», "azul ultramarino», "sinople de Veneza», "verdes finissimos», «rojos muy finos y rosados» «conchas de oro», y «cualquier otros colores que se hallen en Roma para pintar e iluminar, que sean finos, así por casa del peregrino como en la Strada do Peregrino», todo por el precio de 70 escudos de oro ${ }^{29}$. El interés manifestado por Dña. Catarina sobre la calidad de los materiales para los fines previstos la llevó entonces a solicitar a un artista de la corte, Francisco de Holanda, la redacción de un rol de materias primas para comprar, que acompaña esa interesante misiva. Casi treinta años después, de nuevo la misma reina solicitaba al embajador en Roma la adquisición de pigmentos y pinturas inexistentes en el mercado interno, en este caso siguiendo las indicaciones precisas que su pintor Salzedo le sugiere.

En una carta enviada al embajador Tello de Meneses el 6 de diciembre de 1571 la reina trata no sólo de un retrato del malogrado D. Sebastião que se iba pintando (por Salzedo ¿), sino también de los colores «azul ultramarino» que había solicitado para las tablas de Belém, continuando sin embargo a faltar la «laca», que pidió con urgencia pues la pintura se encontraba ya avanzada. En octubre de 1572, la fábrica 'catalinista' de Belém - arquitectura de la capillapanteón, decoración tumular con pares de elefantes, paneles del retablo, vidrieras oriundas de Venecia - estaba totalmente concluida en la fecha de las imponentes fiestas de inauguración oficial de la capilla mayor y de traslado de los huesos de los reyes para el nuevo espacio. El día 13 de ese mes de 1572, sabemos por un relato anónimo sobre el «traslado de los cuerpos de los reyes», guardado en Simancas que el recinto fue consagrado por D. Jorge de Ataíde, obispo de Viseu, en festiva ceremonia a que asistió toda la corte portuguesa y, entre otras dignidades extranjeras, el embajador D. Juan de Borja, con la misa celebrada por el Cardenal-Infante D. Enrique y sermón predicado por el teólogo Diogo de Paiva de Andrade, un activo participante en el Concilio de Trento.

\footnotetext{
${ }^{27}$ Cfr. Julián Zarco Cuevas, Los pintores italianos en San Lorenzo del Escorial, Madrid, 1931.

${ }^{28}$ Frei Manuel Bautista de Castro, Cronica do Maqximo Doutor e Principe dos Patriarcas São Jeronimo, particular do reyno de Portugal, dedicado a D. João V, ANTT, mss. 270, $1^{\text {a }}$ parte; cfr. también J. da Felicidade Alves, ob. cit., 1991.

${ }^{29}$ Rafael Moreira, «Novos dados sobre Francisco de Holanda», revista Sintria, vols. I-II (1982-1983), dir. de José Cardim Ribeiro, Sintra, 1988, pp. 619-692, ref ${ }^{a}$ pp. 673-674.
} 
El tiempo de glorias de la capilla-panteón de la dinastía Avis-Beja se interrumpe con la pérdida de la independencia de 1580, para apenas brillar efímeramente cuando se celebran las exequias reales en honra de Felipe II, en 1599, fecha en que la capilla se engalanó con estructuras efímeras de arquitectura, envolviendo una aparatosa máquina de homenaje a Castra Doloris, encargado por el proveedor de las obras reales Gonçalo Pires de Carvalho y con trazas de Nicolau de Frias, según narra una Relação das Exequias del Rey Dom Filippe nosso $S^{o} r$ (Lisboa, 1600). La pérdida de la importancia emblemática de la capilla-panteón y el gradual desinterés por las pinturas componentes (que fueron toscamente repintadas entre 1673-75 por João Baptista Pinto de Castro y de nuevo en 1820 por Inácio da Silva Coelho Valente) explican que sobre el pintor cayese el manto del desinterés, sólo destapado después del reciente proceso de restauración (Atelier Junqueira 220) que, con el levantamiento de cuatro capas de repintes, mostró composiciones con una inesperada opulencia de paleta y una refinada finura de dibujo.

\section{Sentido de la pintura de Salzedo}

La figura del romanizado Salzedo, pintor de la corte portuguesa de Dña. Catarina de Austria y de D. Sebastião, asume testimonio elocuente de como los modelos más eruditos del manierismo italiano penetraron en el gusto peninsular. Lejos de tratarse de un modelo con epidérmica asimilación, se verifica que al final los repertorios artísticos manieristas penetraron fuerte y profundamente, respondiendo - hasta que la Contrarreforma tridentina impuso sus modelos «reformados» $\mathrm{y}$ «decorosos»- como lenguaje refinado, si no revolucionario que toca el encargo aristocrático y se insinúa también en las grandes obras de señal religiosa.

El caso de la capilla mayor de Santa Maria de Belém, donde la osada arquitectura proyectada por Jerónimo de Ruão se entiende bien con la pintura de Salzedo — ambas conviviendo en el mismo discurso romano- es ejemplar. Si el arquitecto tomó ese modelo para los juegos de distorsión del espacio, el dibujo profano de los arcosolios tumulares, el contrastado chiaroscuro de los mármoles de color el reticulado de los marcos de los ventanales achaflanados, las sinuosas escalinatas en caracol en los cuerpos cilíndricos de los ángulos, temas miguelangelescos como los bancos reclinatorios (similares a las finestre ingenocciate de la Biblioteca Laurenziana) y la utilización arrítmica de los órdenes clásicos ${ }^{30}$, por su lado el pintor tomó el gigantismo de las figuras, su prospecto de «esculturas vivas», la anchura del entorno y el espectáculo articulado de la narración, para discurrir sobre el tema de la Pasión de Cristo, servido por un dibujo irreprensible, que acentúa la veracidad dramática de las escenas y revela la misma elaborada influencia. La reina procuró que el pretendido italianismo de vanguardia fuese cumplido en el panorama artístico de la capilla, en un discurso donde la tradición del espíritu humanista y la grandilocuente modernidad de las formas cohabitan ${ }^{31}$. El «clasicismo manierista de la capilla, avivado por notas de ironía quebrando la pompa libresca de las órdenes y la severidad casi militar del exterior, en un gusto decorativo por sutiles combinaciones cromáticas por el ornamento flamenco», revelaba, como dice Rafael Moreira, nuevas «cualidades de estilo, individualizado y nervioso, que no serían particularmente gratas para los círculos de

${ }^{30}$ Cfr. George Kubler, Portuguese Plain Architecture between Spices and Diamonds, 1521 to 1706, Harmondsworth, 1976; Jorge Henrique Pais da Silva, Estudos sobre o Maneirismo, ed. Estampa, Lisboa, 1983; e António de Oriol e Trindade, Da Capela-Panteão de Santa Maria de Belém ao Real Mosteiro de São Vicente de Fora, tesis de Mestrado, Facultad de Letras de Lisboa, 2002.

${ }^{31}$ Sylvie-Deswarte, «Francisco de Holanda e o Mosteiro dos Jerónimos», in Jerónimos - quatro séculos de pintura, cit., pp. $40-67$.

$A E A$, LXXVI, 2003, 303, pp. 249 a 265 
poder y la visión de Estado del taciturno Cardenal D. Henrique» ${ }^{32}$. Se comprende, por eso , el interés de Felipe II en seguir de lejos la empresa jerónima y opinar sobre su realización, llegando al punto de que en 1568 solicita al embajador D. Francisco Pereira una «traza» de la capilla, que le aseguraban que iba a quedar «primorosa», hecho importantísimo que confirma la atención con que acompañaba esta polémica obra áulica.

Tal como sucedió con Gaspar Becerra y Benito Rabuyate en Castilla, Pietro Morone en Aragón, Pablo de Céspedes en Córdoba, Mateo Pérez de Alesio en Sevilla, António Campelo y Gaspar Dias en Lisboa - todos ellos herederos del modelo romano de circa 1550 y sus intérpretes más o menos fieles-, Salzedo asumió en la obra pictórica realizada en Portugal la tradición directa del Manierismo romano y lo probó con localizado éxito durante su estancia en Lisboa, bajo la protección de Dña. Catarina. El peso de los años que con total seguridad pasó en Roma contó mucho en su formación estética y le amoldó los repertorios piombescos y miguelangelescos que tan fielmente utilizó. Ignoramos si, en el caso de haber tenido una vida más larga, no habría alcanzado más altos vuelos, después de la Unión Ibérica, en grandes empresas castellanas. El hecho es que, fallecido prematuramente, su estilo refinado y anticlásico apenas puede germinar en Portugal (sino puntualmente, en ciertas obras de Francisco Venegas y de António Leitão), frente a los nuevos vientos contrarreformistas que soplaban e imponían nuevas directrices de control artístico, que no sólo en Portugal (ya bajo el cetro de la Unión Ibérica), sino en toda la Península, definirán los caminos pictóricos del final del siglo XvI.

(traducción de María TeResa Montes)

N.F.: Estando este texto en fase de pruebas tipográficas, el historiador de arte señor Gonzalo Redín Michaus, becario de la Escuela Española de Historia y Arqueologia del CSIC en Roma, tuvo la amabilidad de informarnos del descubrimiento de un documento inédito fechado en la Ciudad Papal en 1558 donde se refiere un «Lorenzo Sanzedo pittor» (sic), que no es otro que el que aquí hemos tratado, documentado junto al pintor Gaspar Becerra en obras para el Cardenal Juan Álvarez de Toledo. La preciosa indicación inédita (que Gonzalo Redín publicará integralmente en su tésis) confirma todas nuestras deducciones en relación a la estancia romana de Salzedo y sobre el medio de trabajo en que se movía. El artista surge relacionado, también, con un clérigo portugués, Francisco de Barros, lo que hace pensar que estuviese en Roma como becario de la corte lusitana y frecuentando los mismos círculos artisticos de Daniele da Volterra y sus seguidores.

\section{DOS CARTAS DEL EMBAJADOR FRANCISCO PEREIRA A LA REINA DÑA. CATARINA SOBRE LA OBRA DE PINTURA DEL MONASTERIO DE LOS JERÓNIMOS EN LISBOA}

«Raynha. Por este correo que chegou a esta Corte a xxix do pasado recebi duas cartas de V. Alteza, em huma me diz o muito Contentam.to com que fica de lhe nosso señor deixar ver El Rey nosso señor Entrando em seu governo com taes partes e callidades para os elle reger e governar como vossa Alteza desejar, espero na sua miz ${ }^{a}$ que esta e outros muitos guostos e contentamentos vera Vossa Alteza e ajudará a cassar os filhos del rey nosso señor e sua Alteza tão bem deve dar muitas graças a Ds de ter vossa Alteza por ajudadora aos trabalhos de seu governo por que com tal ajuda e tanta prudençia e cristandade seguramente o pora em porto seguro, a Princesa nosa Señora se alegrou tanto com esta nova como vosa Alteza vera. Ma carta que escrevo a El Rey N. S. e asy a El Rey responde ao que lhe V. A. mandou dizer: (...) Quanto ao Pintor que me Vossa Alteza manda lhe busque que se chama fr.co flores nõ he noticia de tal homem, aquy esta hum que chamão urbino que me dizem he o melhor official que há nesta terra tirando o que pintou o reetavolo do moestr ${ }^{o}$ da Princesa nossa $\mathrm{Sr}^{a}$ que chamavão becerra que morreo avera dez ou doze dias, Aquy há outro tão bem ytalliano, mas este Pinta a fresco e em paredes, como vir El Rey lhe fallarey e saberey delle se este Urbino se sera homem pera emprender nessa obra. A Princesa tão bem Anda buscando hum pintor pera lhe fazer os dous rretavolos dos Altares daquella sua ygr ${ }^{a}$, hum hade ser de são sebastião pera amor de seu filho e o outro de são joão por el rey que esta em gloria, e o rretavolo grande deste moestr ${ }^{o}$ de sua Alteza he muy formoso, todolos painees são de pedra negra de genoa, toma muy bem A tinta e são Incurrutiveis, Ando buscando a traça della pera a mandar a Vossa Alteza como a ouver a enviarey. Madrid, a 3 de ffevr ${ }^{\circ}$ de 1568 ».

\footnotetext{
${ }^{32}$ Rafael Moreira, «Arquitectura: Renascimento e Classicismo», História da Arte Portuguesa de Círculo de Leitores, dirección de Paulo Pereira, vol. I, Lisboa, 1995, p. 355.
}

$A E A$, LXXVI, 2003, 303, pp. 249 a 265 
«Raynha. (...) A nove do presente falley a El Rey no neg ${ }^{\circ}$ da Inffanta D. $\mathrm{M}^{\mathrm{a}}$ em que me sayo hum despacho de que me não satisfiz. Faleilhe no Pintor fr.co froles que V. M. queria pera o rretavolo de belem, dissem que erão tres irmãos, que hum fazia Azulejos pintados e que lhe fizera muita obra desta em tallavera, que morreo avia pouco, os dous hum era Escultor e que o ffr.co flores era Pintor e muito bom official e que estes dous estavão em frandes Ao tempo da nossa Partida, e que agora não há nenhuma nova delle nem se he saydo de frandes por que lhe parece mas que se affirma que elle não andava bem nos neg ${ }^{\circ}$ s da relegião, que este que agora aqui morreo era muito bom official, e que ho orbino sobre que escrevy a V.A. dizião que hera rezoado official e que tinha feito Algumas obras mas que não as tinha visto e que lhe parecia bem Pintasse o Retavollo em pedras por que era a pintura perpetua sem rego da madr ${ }^{a}$ abrir nem se encorear principalmente e nessa terra que he quente e que por tempo poderia receber dano, e que de Genoa viria façilmente as pedras pera ysso. Perguntou-me muito particularmente pella obra da capella como estava que lhe dizião hia perfeitissimamente acabada. Madrid 11 de Fevereiro de 1568». 